\title{
FACULTAD DE RESOLVER CONTROVERSIAS DE LÍMITES TERRITORIALES ENTRE ENTIDADES FEDERATIVAS. LA INCONVENIENCIA DE LA REFORMA CONSTITUCIONAL DE LOS ARTÍCULOS 46, 73, 76 Y 105 DE LA CPEUM DEL AÑO 2005.
}

\author{
Land boundaries dispute solving competence between states. The inconvenience \\ of the 2005 constitutional reform of the articles 46, 73, 76 \\ and 105 of the Mexican Political Constitution.
}

Vicente Vázquez Bustos ${ }^{1^{*}}$

Sumario:

1. Introducción. 2. Antecedentes. 3. Necesidad de contar con mecanismos claros para definir las controversias de límites territoriales. 4. Reforma constitucional de 2005. 5. Reforma constitucional de 2012. 6. Crítica a la reforma constitucional de 2005, a manera de conclusión. 7. Bibliografía.

Resumen. Toda Estado para existir como tal debe de contar con un territorio, a partir de esta premisa fundamental es que se desarrolla un análisis de la forma y mecanismos constitucionales que han existido a lo largo de la historia mexicana para resolver los conflictos de límites entre las entidades federativas.

Especial atención merece la reforma publicada en el Diario Oficial de la Federación el 8 de noviembre de 2005, que facultó al Senado de la República a efecto de que pueda sancionar los convenios amistosos que sobre sus respectivos límites celebren los estados; así como para que pueda establecer de manera definitiva los límites de las entidades federativas que lo soliciten, a efecto de terminar con las diferencias que estos puedan tener relativas a los límites de sus territorios; y la "contra reforma" que a la misma se implementa con la reforma publicada en el Diario Oficial de la Federación el 15 de octubre de 2012, donde se devuelve dicha facultad a nuestro Máximo Tribunal, realizando una crítica a la reforma del año 2005, por ser una reforma constitucional mal planeada y peor ejecutada.

Palabras clave: Comisión de Limites Territoriales entre Entidades Federativas; Límites territoriales; Senado de la República; Suprema Corte de Justicia de la Nación; Naturaleza jurídica; y Naturaleza política.

Abstract. All state to exist as it should be, it must have a territory. From this fundamental premise is that it develops an analysis of form and constitutional arrangements that have existed throughout Mexican history to resolve boundary disputes between entities states.

Special attention is required of the reform published in the Official Journal of the Federation

\footnotetext{
${ }^{1}$ Licenciado en Derecho y Maestro en Fiscal. Catedrático del Departamento de Gestión Pública, División de Derecho, Política y Gobierno de la Universidad de Guanajuato.
} 
on November 8, 2005, which empowered the Senate to the effect that can punish amicable agreements on their respective boundaries that held the states, as well as to enable establish definitively the limits of the states that so request, in order to end the differences that they may have concerning the limits of their territory, and "counter-reform" that it is implemented with the reform published in the Official Journal of the Federation on Octover 15, 2012, where that power is returned to our highest court, in this year, making a criticism of the reform of 2005, as aconstitutional reform badly planned and worse executed.

Keywords: Territorial Boundar Commission between federal entities, territorial limits, Senate, Supreme Court of the Nation, Legal Status, and Political Status.

\section{INTRODUCCIÓN}

Toda constitución en su parte orgánica debe aspirar no sólo a estructurar y organizar el poder estatal, sino también a establecer los instrumentos, mecanismos y procedimientos a través de los cuales sus entidades - como en el caso mexicano lo son los estados y el Distrito Federal-, resuelvan los problemas propios de su esencia y funcionamiento cotidiano. Asimismo, la Ley Fundamental debe buscar tal objetivo atendiendo a la armonía del Estado y sus componentes orgánicos, asignando atribuciones de acuerdo a la naturaleza de sus órganos, ya que si bien no se desconoce que el principio de separación de poderes no es inflexible, sí es claro que determinadas atribuciones deben recaer en quien esté mejor perfilado constitucionalmente para el caso.

En el presente trabajo, se busca analizar la facultad de dirimir los conflictos de límites territoriales entre las entidades federativas, a partir de la reforma a la Constitución Política de los Estados Unidos Mexicanos, donde se le otorgó esta facultad al Senado de la República, en 2005 - facultad que se retiró a la Suprema Corte de Justicia de la Nación- y la reforma donde se devuelve dicha facultad a nuestro Máximo Tribunal, publicada en el Diario Oficial de la Federación el 15 de octubre de 2012.

Como atinadamente señalara en el siglo XIX, Isidro A. Montiel y Duarte «...nada es más fácil que comprender con toda la fuerza de una profunda convicción, que para entender bien nuestro derecho constitucional es de todo punto indispensable estudiar: $1^{\circ}$ Los errores y preocupaciones que necesariamente han venido influyendo en la legislación constitucional.»²

\section{ANTECEDENTES}

El Acta solemne de la declaración de la independencia de la América Septentrional, del 6 de noviembre de 1813, consignó:

«El Congreso de Anáhuac, legítimamente instalado en la ciudad de Chilpancingo de la América Septentrional por las provincias de ella...».3

Por su parte, el Decreto Constitucional para la libertad de la América Mexicana, conocido también como Constitución de Apatzingán, sancionado el 22 de octubre de 1814, estableció:

\footnotetext{
2 Montiel y Duarte, Isidro Antonio, comp., Derecho Público Mexicano, Compilación, México, D.F., 1871, Tomo I, ed. Imprenta del Gobierno en Palacio, p. IX.

${ }^{3}$ Op. Cit. 1, p. 10. 
"Artículo 42. Miéntras (sic) se haga una demarcación exacta de esta América mexicana y de cada una de las provincias que la componen, se reputarán bajo este nombre y dentro de los mismos términos que hasta hoy han reconocidos los siguientes: México, Puebla, Tlaxcala, Veracruz, Yucatán, Oaxaca, Técpam, Michoacán, Querétaro, Guadalajara, Guanajuato, Potosí, Zacatecas, Durango, Sonora, Coahuila y Nuevo reino de León».4

El artículo $8^{\circ}$ del Acta Constitutiva de la Federación Mexicana, de 31 de enero de 1824, estableció la posibilidad de modificar la composición de los estados:

«Art. $8^{\circ}$. En la Constitución se podrá aumentar el número de los Estados comprendidos en el artículo anterior, y modificarlos según se conozca ser mas conforme a la felicidad de los pueblos». 5

Si bien no existía todavía una clara referencia a la autonomía de los estados para decidir libre y amistosamente sus límites, sí se planteó cierta apertura para que se decidiera conforme a lo más conveniente para los habitantes.

Si bien a continuación se realiza el estudio de los diversos textos constitucionales vigentes en el país, se pone énfasis en las tres grandes constituciones federales que nos han regido, las que, como señala Emilio O. Rabasa «...fueron precedidas por una revolución; la Constitución de 1824 por la revolución de independencia; la del 57, por la Revolución de Ayutla y la del 17, por la Revolución de este siglo en sus dos fases, la de 1910 con Medero y la de 1913 con Carranza. Y las tres tienen especiales y grandes problemas, aparte del inherente a hacer una Constitución.» ${ }^{6}$

La Constitución Federal de los Estados Unidos Mexicanos de 1824, estableció en su artículo 50, la facultad del Congreso para arreglar definitivamente los límites de los estados, sin dejar abierta la facultad para que éstos arreglaran sus límites, disponiendo que se crearía una ley para fijar la extensión y límites de los estados. ${ }^{7}$

Durante el periodo en que se adoptó el Centralismo, en la Sexta de las Siete Leyes Constitucionales de 1836, al tratar la división del territorio nacional se estableció que:

«Art. $1^{\circ}$. La República se dividirá en Departamentos, conforme a la octava de las bases orgánicas. Los departamentos se dividirán en distritos y estos en partidos.» ${ }^{8}$

4 Op. Cit. 1, p. $23 .$.

5 Montiel y Duarte, Isidro Antonio, comp., Derecho Público Mexicano, Compilación. México, D.F., 1871, Tomo I, ed. Imprenta del Gobierno en Palacio, p. 65.

${ }^{6}$ Rabasa, Emilio O., citado por Galeana, Patricia comp., México y sus Constituciones, México, D.F., 1999, ed. Archivo General de la Nación y Fondo de Cultura Económica.

7 A través del Decreto de 19 de Julio de 1828, de determinó - entre otros aspectos- dividir las provincias de Sonora y Sinaloa, así como dividir al territorio conocido como Nueva Vizcaya, en las provincias de Durango y Chihuahua, Op. Cit. 1, p. 244; por medio de decreto del 22 de agosto de 1823, se decretó la provincia de Querétaro, a partir de los partidos de su capital, Cadereita y San Juan del Río, Op. Cit. 1, p. 248; y por Decreto de 14 de octubre de 1823, se formó la provincia del Itsmo, a partir de las jurisdicciones de Acayucan y Tehuantepec, Op. Cit. 1, p. 250. En el Acta Constitutiva y de reformas, del 18 de mayo de 1847, se erigió en el artículo 6, el Estado de Guerrero, compuesto por los distritos de Acapulco, Chilapa, Tasco (sic) y Tlapa y la municipalidad de Coyucan, Op. Cit. 2, p. 406, por citar varios ejemplos de la división del territorio nacional. ${ }^{8}$ Op. Cit. 4, p. 63. 
De modo que correspondía al Poder Legislativo, y en particular a la Cámara de Diputados, conforme a la tercera ley constitucional (artículo 44 fracción XVI) el aumentar o disminuir por agregación o división los departamentos que conformaban la República Mexicana.

No fue sino hasta el artículo 22 del Voto Particular de la Minoría de la Comisión Constituyente de 1842, cuando se estableció la capacidad de los estados para arreglar sus límites por convenios amistosos, con la aprobación del Congreso General y solo en caso de que no pudieran lograr acuerdo en los puntos contenciosos, fallaría la Suprema Corte de Justicia.

Las Bases Orgánicas de la República Mexicana, de 1843, establecieron:

«Art. $3^{\circ}$. El número de los Departamentos y sus límites se arreglarán definitivamente por una ley, continuando por ahora como existen...».9

El artículo 110 de la Constitución Política del 5 de febrero de 1857, introdujo el artículo — que hoy conocemos bajo el numeral 46-, donde estableció que deben sujetarse a la aprobación del Congreso de la Unión sus arreglos por convenios amistosos sobre cuestiones de límites. ${ }^{10}$

La vigente Constitución de 1917, al regular en sus artículos 42 y 43 al territorio nacional, así como a las partes integrantes de la Federación, es omisa, sin embargo, respecto al señalamiento sobre los límites de estas últimas, haciendo referencia únicamente a situaciones previas como es el caso de lo establecido en su artículo 45, al establecer que:

«Los Estados de la Federación conservan la extensión y límites que hasta hoy han tenido, siempre que no haya dificultad en cuanto a éstos».

Y consignar el artículo 46 -en su texto original en 1917- que:

«Los estados que tuvieren pendientes cuestiones de límites, las arreglarán o solucionarán en los términos que establezca la Constitución.»

A este respecto señala Tena Ramírez que «...cuando el actual artículo 45 dispone que los Estados y Territorios conservan la extensión que hasta hoy han tenido, se refiere a una situación de hecho que no ha sido esclarecida ni determinada por ninguna ley» ${ }^{11}$

El artículo solo ha tenido tres reformas, la primera, publicada en el Diario Oficial de la Federación el 17 de marzo de 1987, con el siguiente texto:

«Los estados pueden arreglar entre sí, por convenios amistosos, sus respectivos límites; pero no se llevarán a efecto esos arreglos sin la aprobación del Congreso de la Unión.»

La segunda reforma, es justamente la de 2005, que se aborda en el punto 4 del presente artículo, y la tercera, la de 2012 .

\footnotetext{
9 Op. Cit. 4, p. 430.

${ }^{10}$ Montiel y Duarte, Isidro Antonio, comp., Derecho Público Mexicano, Compilación, México, D.F., 1871, Tomo IV, ed. Imprenta del Gobierno en Palacio, p. 943.

${ }^{11}$ Tena Ramírez, Felipe, citado por Cruz Barney, Oscar, comentario al artículo 47 en Constitución Política de los Estados Unidos Mexicanos, comentada y concordada. México, D.F., 20o9, Tomo II, Vigésima edición, Instituto de Investigaciones Jurídicas de la U.N.A.M., ed. Porrúa, p. 291.
} 
Resulta primordial señalar la importancia que detenta la división territorial de un país, que tiene como sistema de gobierno la fórmula federal. En un país de régimen federalista, las partes integrantes del mismo son consideradas como un todo en virtud de que estas pertenecen al régimen en razón de un pacto federal. Es por ello que el territorio es un elemento que da vida, fuerza y riqueza al Estado y no cabe duda que la geografía determina muchas veces la política de un Estado de manera decisiva.

De lo anterior se establece que los territorios no son simplemente divisiones territoriales, ya que estos cuentan con soberanía para dictarse sus propias leyes y gobernarse a sí mismas. $\mathrm{Al}$ respecto, es necesario que todo Estado cuente con certidumbre en cuanto a su territorio. La importancia del territorio se refleja en la historia de nuestro país, en virtud de que desde sus inicios México ha sufrido innumerables cambios políticos, geográficos, 12 culturales y económicos en este sentido, tiene especial importancia para el fortalecimiento del sistema federal, pues tiene que ver con la distribución territorial del poder, en jurisdicciones y ámbitos distintos.

De forma que si bien el territorio nacional lo integran las entidades federativas, éste no es propiedad de los estados ni del Gobierno Federal, sino que pertenece a todos los mexicanos, no individualmente considerados, sino como una comunidad de intereses con un pasado, un presente y un futuro comunes.

Por lo tanto, la nación mexicana cuando se refiere al territorio de las entidades federativas, no consigna ningún derecho de propiedad de los estados miembros, pues en realidad se está estableciendo un área geográfica, que será la medida espacial de cada una de las jurisdicciones estatales.

Si bien se establecen o enuncian cuales son las partes integrantes de la Federación, no se definen dos conceptos importantes: cuáles son los límites de cada una de las entidades federativas y, derivado de esto, cuáles serían los medios de solución en caso de duda o disputa sobre determinados territorios de las entidades federativas.

\footnotetext{
${ }^{12}$ Baste recordar que nuestro territorio ha tenido varias escisiones, como lo fue en un inicio la separación de la Provincia de Guatemala, después de que el presidente de la Junta Provisional Consultiva, decretó la anexión de las provincias centroamericanas al Imperio Mexicano, que incluía a la Provincia de Guatemala, mediante acta que recabó la decisión mayoritaria de los ayuntamientos, pero dicha unión duró hasta la abdicación de Agustín de Iturbide en marzo de 1823; Chiapas, se convirtió en estado de México el 14 de septiembre de 1824 tras la realización de un plebiscito popular — durante la etapa colonial estaba integrado en la Capitanía General de Guatemala-; luego con los Tratados de Velasco de 1836, Antonio López de Santa Anna reconoció la independencia de la República de Texas; por el Tratado de Guadalupe Hidalgo — oficialmente llamado Tratado de Paz, Amistad, Límites y Arreglo Definitivo entre los Estados Unidos Mexicanos y los Estados Unidos de América- firmado al final de la Guerra de Intervención Estadounidense, en 1848, se estableció que México cedería más de la mitad de su territorio, que comprende la totalidad de lo que hoy son los estados de California, Nevada, Utah, Nuevo México y Texas, además de renunciar a todo reclamo sobre Texas y la frontera internacional se establecería en el Río Bravo. El 30 de diciembre de 1853 se firmó el Tratado de la Mesilla, por el que el gobierno de Santa Anna vendió 76,845 kilómetros cuadrados adicionales de terreno, al sur de los actuales estados de Arizona y Nuevo México. Finalmente, está el caso del arbitraje del Rey de Italia Víctor Manuel III, cuyo laudo en 1931, adjudicó la isla de la Pasión —Clipperton — sobre en el océano pacífico, a Francia en el periodo del Presidente Pascual Ortiz Rubio y que orilló a reformar el artículo 42 de la Constitución para sacar a dicha isla como parte del territorio nacional (D.O.F. del 18 de enero de 1934).
} 


\section{REFORMA CONSTITUCIONAL DE 2005}

A través del Decreto publicado en el Diario Oficial de la Federación el 8 de noviembre de 2005, se reformó el párrafo único y se adicionaron un segundo y tercer párrafos al artículo 46; se derogó la fracción IV del artículo 73; se adicionaron las fracciones X y XI, pasando la entonces fracción X a ser fracción XII del artículo 76; y se reformó la fracción I del artículo 105, de la Constitución Política de los Estados Unidos Mexicanos, reforma que tuvo como objeto medular — según se adujo- contar con mecanismos claros para definir las controversias de límites territoriales.

A través de esta reforma se propuso facultar al Senado de la República a efecto de que pueda sancionar los convenios amistosos que sobre sus respectivos límites celebren los estados; así como para que pueda establecer de manera definitiva los límites de las entidades federativas que lo soliciten, a efecto de terminar con las diferencias que estos puedan tener relativas a los límites de sus territorios, ello con una votación calificada de dos terceras partes de los senadores presentes.

Asimismo, estableció la atribución a favor de la Suprema Corte de Justicia de la Nación para que ésta, a instancia de la Entidad Federativa interesada, por la vía de la Controversia Constitucional pueda conocer únicamente de los conflictos derivados de la ejecución del decreto que fije los límites.

\subsection{ORIGEN DE LA REFORMA.}

Se encuentra en la iniciativa presentada el 7 de octubre del año 2004, por el Senador Héctor Michel Camarena, miembro del Grupo Parlamentario del Partido Revolucionario Institucional.

Posteriormente el 9 de diciembre de 2004, fue aprobado por las Comisiones de Puntos Constitucionales y de Estudios Legislativos Primera, de la Cámara de Senadores, el dictamen de la iniciativa enunciada, y fue aprobado el 14 de diciembre de 2004.

Recibida la Minuta con Proyecto de Decreto en la Cámara de Diputados, el 1 de febrero de 2005, el Presidente de la Mesa Directiva dictó trámite de recibo y ordenó su turno a la Comisión de Puntos Constitucionales, para su estudio y dictamen; radicándose por la Comisión de Puntos Constitucionales el 15 de marzo de 2005. En sesión de la Comisión de Puntos Constitucionales de la Cámara de Diputados de fecha 27 de abril de 2005, se aprobó la Minuta de referencia, realizándose modificaciones a la misma, sin perder el sentido y la trascendencia de la iniciativa. En sesión ordinaria de la Cámara de Diputados de 28 de abril de 2005, se sometió a votación del Pleno el dictamen, aprobándose por 352 votos a favor, 14 votos en contra y una abstención; ordenándose su remisión a la colegisladora para los efectos del artículo 72 inciso e) 13 de la Constitución Política de los Estado Unidos Mexicanos.

\footnotetext{
13 «E. Si un proyecto de ley o decreto fuese desechado en parte, o modificado, o adicionado por la Cámara revisora, la nueva discusión de la Cámara de su origen versará únicamente sobre lo desechado o sobre las reformas o adiciones, sin poder alterarse en manera alguna los artículos aprobados. Si las adiciones o reformas hechas por la Cámara revisora fuesen aprobadas por la mayoría absoluta de los votos presentes en la Cámara de su origen, se pasará todo el proyecto al Ejecutivo, para los efectos de la fracción A. Si las adiciones o reformas hechas por la Cámara revisora fueren reprobadas por la mayoría de votos en la Cámara de su origen, volverán a aquella para que tome en consideración las razones de ésta, y si por mayoría absoluta de votos presentes se desecharen en esta segunda revisión dichas adiciones o reformas, el proyecto, en lo que haya sido aprobado por ambas Cámaras, se pasará al Ejecutivo para los efectos de la fracción A. Si la Cámara revisora 
El 28 de abril de 2005, se recibió en el Senado de la República la Minuta con Proyecto de Decreto, turnándose por el Presidente de la Mesa Directiva a las Comisiones Unidas de Puntos Constitucionales y de Estudios Legislativos, Primera, para su estudio y dictamen; suscribiéndose este el 28 de abril de 2005, aprobando las modificaciones hechas por la colegisladora; discutiéndose el dictamen con dispensa de segunda lectura, en la sesión de Pleno del Senado el 21 de junio de 2005, resultando aprobado por 80 votos a favor.

Cabe destacar que en los dictámenes legislativos, se adujo de manera profusa; así la Comisión de Puntos Constitucionales de la Cámara de Diputados, suscribió el dictamen, realizando modificaciones a la Minuta que le fue remitida por el Senado de la República, argumentando que:

«... hay dos consideraciones que apuntan hacia la Cámara de Senadores como el órgano federal idóneo para resolver esta clase de diferendos. La primera de ellas se basa en nuestra historia constitucional la cual nos deja ver que ha sido la intención y el espíritu del Constituyente Permanente el que los límites territoriales sean determinados legalmente. Sin embargo, el que tal determinación de límites deba hacerse a través de una Ley Reglamentaria no ha sido la mejor solución, lo cual no invalida la conveniencia de que la misma sea definida a través de un acto material y formalmente legislativo.

El argumento anterior es aún más claro si atendemos a la segunda de nuestras consideraciones. El territorio, como lo apunta la mayoría de los teóricos del Estado, es uno de los elementos necesarios y previos de éste. En él se expresan todos los demás elementos del Estado: su población, y el poder expresado a través de un orden jurídico que en el caso de los Estados federales está compuesto de su esfera nacional y de su ámbito local.

No en balde Jellinek define al Estado como una corporación territorial dotada de poder de mando originario. Por tanto el territorio, al ser un elemento de tal trascendencia en la vida de un Estado debe ser definido, establecido y resguardado constitucional y legalmente. Es tan sólo cuando hay diferencias o contención sobre la aplicación o interpretación de la ley cuando el poder encargado en esencia de la función jurisdiccional debe intervenir, en tanto que aquel diseñado para elaborar leyes es quien debe regular, en principio, los aspectos esenciales de la estructuración y organización estadual.

De manera específica se estima que la Cámara de Senadores del Congreso de la Unión, fiel a su naturaleza originaria de garante del pacto federal, es el órgano constitucional mejor abocado para la resolución de conflictos territoriales entre entidades federativas a través de la determinación legislativa de los límites de los estados y el Distrito Federal, cuando estos así lo soliciten.

Al establecer tal determinación como una facultad exclusiva del Senado se evita la prolongación de la misma que sería propia de un acto bicameral. Asimismo, y al menos en origen, el Senado contiene una representación más equilibrada de las entidades federati-

insistiere, por la mayoría absoluta de votos presentes, en dichas adiciones o reformas, todo el proyecto no volverá a presentarse sino hasta el siguiente período de sesiones, a no ser que ambas Cámaras acuerden, por la mayoría absoluta de sus miembros presentes, que se expida la ley o decreto sólo con los artículos aprobados, y que se reserven los adicionados o reformados para su examen y votación en las sesiones siguientes.» 
vas en contraste con la Cámara de Diputados, lo que garantiza una apreciación más justa y equitativa de los conflictos limítrofes. $»^{14}$

Asimismo, la Cámara de Diputados en su carácter de revisora, consideró conveniente precisar que la aprobación de los decretos emitidos por el Senado, sea por el voto de las dos terceras partes de los individuos presentes, considerando que con ello se daría mayor certeza y seguridad jurídica a decisiones sobre conflictos cuya naturaleza los identifica como de la más alta complejidad por sus efectos e impacto de toda índole, en el desarrollo de las regiones implicadas; por lo que la votación calificada, con toda seguridad — según la argumentación del dictamen legislativo-, sería una limitante a la politización de estos conflictos, y permitiría una mayor aceptación de las correspondientes resoluciones por parte de las entidades federativas involucradas en estos diferendos limítrofes.

Resulta importante destacar que se consideró conveniente que los decretos del Senado por los cuales se resuelvan conflictos limítrofes tengan el carácter de definitivos e inatacables. Ello por varias razones, la primera a fin de evitar la recurrencia de los problemas que se pretenden resolver al inhibir que se acuda ante la Suprema Corte de Justicia de la Nación a impugnar el fondo del dictamen senatorial, así como su aprobación misma; y la segunda, consiste en la conveniencia de dirimir en definitiva conflictos que en su mayoría datan de mucho tiempo atrás con las secuelas negativas que ello ha implicado en la relación entre entidades y comunidades regionales.

Lo anterior no obstaría para que la Suprema Corte pueda conocer en controversia constitucional, y a solicitud de la entidad federativa interesada, de aquellos conflictos derivados de la ejecución del decreto de la Cámara de Senadores por el cual se resuelvan diferendos territoriales.

En tanto que en el Senado de la República, las Comisiones Unidas de Puntos Constitucionales y de Estudios Legislativos, Primera, suscribieron el dictamen aprobatorio de la Minuta que les fue turnada por la colegisladora, considerando como argumento para la aprobación de la propuesta, el subsanar una laguna jurídica existente en nuestra Carta Magna, en materia de límites territoriales, considerando que la vía legislativa y mediante el ejercicio de una facultad exclusiva de dicha Cámara es la mejor vía para resolver amistosamente o a instancia de parte, los conflictos de límites entre las partes integrantes de la Federación.

Señaló el dictamen la conformidad con las adecuaciones realizadas por la colegisladora, toda vez que con las mismas se fortalecería la propuesta inicial pero a su vez se dejaron intocados los temas fundamentales de la iniciativa, como son:

«1. Llenar un vacío jurídico que existía en el artículo 46 constitucional, adicionándole un párrafo segundo, mediante el cual a falta de acuerdo, cualquiera de las partes podrá acudir ante la Cámara de Senadores, quien actuará en términos del artículo 76, fracción IX, de la Constitución.

2. Que las resoluciones del Senado de la República serán definitivas e inatacables, esto es resuelven el fondo de los conflictos de límites entre las entidades federativas.

\footnotetext{
${ }^{14}$ Dictamen de la Comisión de Puntos Constitucionales, con Proyecto de Decreto que reforma el único párrafo y se adicionan un segundo y tercer párrafos al artículo 46; se deroga la fracción IV del artículo 73; se adicionan las fracciones X y XI, pasando la actual fracción X a ser fracción XII, del artículo 76; y se reforma la fracción I del artículo 105 de la Constitución Política de los Estados Unidos Mexicanos. Gaceta Parlamentaria de la Cámara de Diputados del H. Congreso de la Unión del 28 de abril de 2005. Consultable en: http:// gaceta.diputados.gob.mx/
} 
3. Que la Suprema Corte de Justicia de la Nación, solamente interviene en los conflictos derivados de la ejecución del decreto del Senado de la República, a instancia de parte interesada y a través de la controversia constitucional.

4. Que con el decreto definitivo e inatacable del Senado de la República, las entidades federativas tienen un camino jurídico por el que habrán de transitar, para dirimir sus conflictos derivados de la ejecución de dicho decreto; y la Suprema Corte de Justicia de la Nación tendrá en el decreto la base jurídica para decidir, ahora sí, conforme a la ley y mediante la controversia constitucional los conflictos derivados de la ejecución del decreto.

5. El establecimiento de la Comisión de Límites del Senado de la República, que le dará curso a las solicitudes de establecimiento de límites de las entidades federativas, y con ello, la vía jurídica y política que por su trascendencia estos asuntos requieren.

6. La remisión de inmediato al Senado de la República, de las controversias constitucionales que se encuentren en trámite, con todos sus antecedentes, ante la Suprema Corte de Justicia de la Nación, con motivo de conflictos limítrofes entre entidades federativas, para que la citada Cámara en plenitud de facultades constitucionales, proceda a establecerlos por decreto de manera definitiva. $\rangle^{15}$

Asimismo, manifestaron su coincidencia con la modificación del artículo tercero transitorio, en el sentido de que, al ser el Senado de la República el facultado para resolver los conflictos limítrofes, debía remitir la Suprema Corte los asuntos en trámite, para su resolución definitiva por la Cámara Alta.

\subsection{TEXTO DERIVADO DE LA REFORMA CONSTITUCIONAL DE 2005}

Con la reforma constitucional se estableció que sea el Senado de la República quien resuelva de manera definitiva e inatacable, mediante decreto, los conflictos sobre límites territoriales de los estados; ello en razón de que el Senado — se consideró así- era el órgano federal idóneo para resolver esta clase de diferendos, pues la Cámara de Senadores, conforme su naturaleza originaria de garante del pacto federal, se valoró era el órgano constitucional mejor abocado para resolver los conflictos territoriales entre entidades federativas a través de la determinación legislativa de los límites de los estados y el Distrito Federal, cuando éstos así lo soliciten.

Además, se argumentó que al establecer tal determinación como facultad exclusiva del Senado, se evita la prolongación de la misma que sería propia de un acto bicameral. Se señaló que fortalecía este argumento el que el Senado está integrado con una representación más equilibrada de las entidades federativas en contraste con la Cámara de Diputados, lo que sin duda alguna, garantizaría una apreciación más justa y sobre todo más equitativa de los conflictos limítrofes. ${ }^{16}$

\footnotetext{
${ }^{15}$ Dictamen de las Comisiones Unidas de Puntos Constitucionales, y de Estudios Legislativos, Primera, con proyecto de decreto mediante el cual se reforma el único párrafo y se adicionan un segundo y tercer párrafos al artículo 46; se deroga la fracción IV del artículo 73; se adicionan las fracciones X y XI, pasando la actual fracción X a ser fracción XII del artículo 76; y se reforma la fracción I del artículo 105, todos ellos de la Constitución Política de los Estados Unidos Mexicanos. Gaceta Parlamentaria del Senado de la República, 21 de junio de 2005. Primer Periodo Extraordinario, Gaceta 113. Consultable en: http://www.senado.gob.mx/index.php?ver $=$ sp $\& m n=2 \& s m=2 \& i d=6781 \& \lg =59$

${ }^{16}$ Cabe destacar en oposición a lo señalado por el Constituyente Permanente que el Senado de la República se compuso de dos senadores por Entidad Federativa y el Distrito Federal después de su restauración en 1874; la Constitución de 1917, mantuvo la conformación, hasta que en 1993 se introdujo el principio de representación proporcional en el Senado,
} 
Así, según José Barragán Barragán «hemos visto y repetido que el Senado se crea para llevar la representación en el Congreso del interés general de los estados miembros de la Unión: el Senado representa a las entidades federativas, el Senado es una gran institución federal, pero, en vigor, no es esencial al sistema. Entre 1857 y 1874 no hubo Senado y nada pasó. Lo que parece ser esencial al sistema federal mexicano es que los estados cuenten con un órgano de representación de sus intereses como entidades federativas, para mantener el equilibrio de la Unión, la igualdad entre los estados y el acierto de la coordinación de la actividad del gobierno federal.» ${ }^{17}$

Así, se estableció que los decretos del Senado por los cuales se resuelvan conflictos limítrofes tengan el carácter de definitivos e inatacables, a fin de evitar la recurrencia de los problemas que se pretenden resolver al inhibir que se acuda ante la Suprema Corte a impugnar el fondo del dictamen.

Finalmente, se modificó la fracción I del artículo 105 constitucional, con la finalidad de hacer expresa la voluntad del Constituyente Permanente, en relación a que el único órgano constitucional facultado para conocer y resolver conflictos limítrofes, fuera el Senado de la República, y que la Suprema Corte de Justicia de la Nación únicamente podría conocer en la materia, mediante controversia constitucional, a petición de parte interesada, de aquellas controversias que versen sobre la ejecución de los decretos que la Cámara de Senadores apruebe al resolver conflictos territoriales entre entidades federativas. Esta modificación buscó la congruencia con lo que se previene en la reforma del párrafo tercero del artículo 46 constitucional, al dejarle competencia a la Suprema Corte, pero solamente para conocer de los conflictos derivados de la ejecución del decreto.

Punto destacado de esta reforma, lo son los dispositivos transitorios que señalaron:

«PRIMERO.- La reforma entrará en vigor al día siguiente al de su publicación en el Diario Oficial de la Federación.

SEGUNDO.- La Cámara de Senadores establecerá dentro del periodo ordinario de sesiones inmediato siguiente a la entrada en vigor del presente decreto, la Comisión de Límites de las Entidades Federativas, la cual se integrará y funcionará en los términos de la ley reglamentaria que al efecto se expida, así como por las disposiciones que para el caso dispongan la Ley Orgánica del Congreso General de los Estados Unidos Mexicanos y el Reglamento para su Gobierno Interior.

TERCERO.- Las controversias que a la entrada en vigor de este decreto se encuentren en trámite ante la Suprema Corte de Justicia de la Nación con motivo de conflictos limítrofes entre entidades federativas, serán remitidas de inmediato, con todos sus antecedentes, a la Cámara de Senadores, a fin de que ésta en términos de sus atribuciones constitucionales proceda a establecerlos de manera definitiva mediante decreto legislativo.»

eligiéndose 3 senadores: 2 por principio de mayoría relativa y 1 por el principio de representación proporcional; y a partir de 1996 se elijen a 4 senadores: 2 por el principio de mayoría relativa, 1 a la primera minoría, y 1 por sistema de lista (una sola circunscripción plurinominal para todo el país). De donde al introducir este nuevo sistema proporcional, se rompe el principio de que el Senado representa el territorio y ahora representa también a la población y a los estados.

17 Torija Aguilar, Jaime et al. El senado mexicano, por la razón de las leyes, México, D.F., 1987, Volumen uno, Senado de la República, LIII Legislatura, p. 201. 


\section{REFORMA CONSTITUCIONAL DE 2012}

Pasados más de seis años de la reforma a los artículos 46, 73, 76 y 105 de la Constitución Política de los Estados Unidos Mexicanos — publicada en el Diario Oficial de la Federación el 8 de noviembre de 2005-, se reformó nuevamente la Constitución en los artículos 46, 76 y 105 - Diario Oficial de la Federación del 15 de octubre de 2012-, y con esta reforma se deroga la fracción XI del artículo 76 constitucional, que contemplaba las facultades del Senado de la República de autorizar mediante decreto aprobado por el voto de las dos terceras partes de los individuos presentes los convenios amistosos que sobre sus respectivos límites celebren las entidades federativas y de resolver de manera definitiva los conflictos sobre límites territoriales de las entidades federativas que así lo soliciten, mediante decreto aprobado por el voto de las dos terceras partes de los individuos presentes; asimismo, se reformó la fracción I del artículo 105 constitucional, para que en concordancia con la modificación al artículo 46 constitucional, se elimine excepción de que la Suprema Corte de Justicia de la Nación conozca en controversia constitucional del conflicto de límites territoriales entre los Estados miembros de la Federación.

\subsection{DICTAMEN DEL SENADO DE LA REPÚBLICA}

Las Comisiones Unidas de Puntos Constitucionales y de Estudios Legislativos de la Cámara de Senadores, dictaminaron cuatro iniciativas con Proyecto de Decreto que reforman los artículos 46, 76 y 105 de la Constitución Política de Los Estados Unidos Mexicanos, con opinión de la Comisión de la Comisión de Límites de las Entidades Federativas, las iniciativas fueron suscritas por los senadores: 1. Ramiro Hernández García (PRI); 2. Humberto Andrade Quezada (PAN); 3. Integrantes de la Junta de Coordinación Política (PAN, PRI, PRD, PVEM, Convergencia y PT); y 4. Héctor Pérez Plazola (PAN).

Las iniciativas, en lo esencial proponían: ${ }^{18}$ (vease anexo 1).

El dictamen, por otra parte, reconoce - de manera implícita- que la necesidad de realizar la «contra reforma» en materia de resolución de límites territoriales, obedece a que se fue incapaz de cumplir en los términos con las obligaciones que se le establecieron al Congreso de la Unión acorde a los artículos segundo y tercero transitorio del Decreto de reforma constitucional de 2005, al consignar en el dictamen:

«En el decreto mencionado, se estableció en el artículo tercero transitorio que: "Las controversias que a la entrada en vigor de este decreto se encuentren en trámite ante la Suprema Corte de Justicia de la Nación con motivo de conflictos limítrofes entre entidades federativas, serán remitidas de inmediato, con todos sus antecedentes, a la Cámara de Senadores, a fin de que ésta en términos de sus atribuciones constitucionales proceda a establecerlos de manera definitiva mediante decreto legislativo."

\footnotetext{
${ }^{18}$ Cuadro comparativo contenido en el Dictamen de las Comisiones Unidas de Puntos Constitucionales y de Estudios Legislativos, con opinión de la Comisión de Límites de las Entidades Federativas, respecto el Proyecto de Decreto que reforma los artículos 46, 76 y 105 de la Constitución Política, en materia de límites territoriales. Gaceta Parlamentaria del Senado de la República del 21 de junio de 2005. Primer Periodo Ordinario. Gaceta 330. Consultable en: http://www.senado.gob.mx/index.php? 
Finalmente, el Senado debía constituir en su estructura la Comisión de Límites de las Entidades Federativas, la cual se integraría y funcionaría en los términos de la ley reglamentaria que al efecto se expida.

Lo anterior es una descripción sintética de la reforma constitucional mencionada previamente, y que a casi 6 años de su entrada en vigor conviene revisar... ${ }^{19}$

Continúa señalando el dictamen senatorial que:

«Como se puede apreciar, esto resultaba requisito sine quanon para que esta Soberanía a través de la Comisión de Límites Territoriales entre Entidades Federativas, dictaminara a partir de los convenios que en su caso, se hubieren presentado por las entidades involucradas y considerando los elementos esenciales siguientes: en primer término definir qué hacer y con base en que fundamento constitucional se analizaban y calificaban las actuaciones jurisdiccionales que obran en cada expediente; para ello se advirtieron las siguientes disyuntivas: a) invalidar las actuaciones jurisdiccionales hasta entonces radicadas en la Suprema Corte; y b) tomar en consideración lo actuado y repercutirlas en el dictamen.

La primera de las opciones señaladas era tanto como decir "borrón y cuenta nueva", pero para que ello surtiera efectos, resultaba indispensable que esta Soberanía declarara invalidado lo actuado por la Suprema Corte de Justicia de la Nación, acto jurídico que nos resultaba inoperante, así como carente de fundamento constitucional, puesto que al Senado le está otorgada por la Constitución la facultad para crear, adicionar, reformar, derogar y abrogar leyes, pero no para invalidar resoluciones del Poder Judicial Federal.

La segunda opción, en donde el criterio que en su caso podría tomar el Senado, es el correspondiente a prescribir que el dictamen se sustentaría como primera premisa de las actuaciones que realizó la Suprema Corte, no obstante, esto también resultaba inoperante, puesto que el procedimiento seguido bajo estricto derecho dejó de serlo en el momento mismo que dio un viraje al transformarse su naturaleza jurídica, así como la vía, los términos y el procedimiento para el desahogo de la litis, es decir en la amigable composición como forma de concluir los conflictos, sin embargo, ésta no tiene cabida en los procedimientos jurisdiccionales, antes bien, ambas formas se excluyen entre sí.

Lo anterior trajo como consecuencia que esta Soberanía ahondara en el principio de la división de poderes, para no invadir la función jurisdiccional que a todas luces es más propia de la Suprema Corte, consistente en este caso en conocer, sustanciar y resolver bajo su plena jurisdicción los conflictos de límites territoriales entre las entidades federativas, en forma uni-instancial, cuya resolución produzca cosa juzgada.

Estas comisiones dictaminadoras, consideran conveniente trasladar la competencia contenciosa que tiene actualmente el Senado para conocer del conflicto limítrofe entre entidades federativas a la Suprema Corte de Justicia de la Nación ya que nuestra Carta Magna consagra el principio de división de poderes (artículo 49) y además establece las facultades de los Poderes Ejecutivo, Legislativo y el Judicial. Por lo que hace al Legislativo federal, de manera específica, la Cámara de Senadores, dentro de sus facultades no dispone ejercer facultades jurisdiccionales, dichas facultades corresponden al Poder Judicial.

\footnotetext{
${ }^{19}$ Op. Cit. 17 .
} 
La Cámara de Senadores es un órgano legislativo, político y representativo, no un órgano jurisdiccional. Y sólo de manera muy excepcional realiza funciones jurisdiccionales en los casos previstos en la Constitución Política.» ${ }^{20}$

De conformidad con el turno otorgado, se contó con la opinión — sin carácter vinculatorio- de la Comisión de Límites de las Entidades Federativas, la cual fue divergente del sentido del dictamen de la Cámara de Senadores al argumentar:

«Insuficiencias de la reforma de diciembre de 2005.

Así pues, pese a la limitación de no poder ejercer la facultad consagrada en la fracción XI del artículo 76 constitucional, las facultades en materia limítrofe de las entidades federativas han sido efectivamente ejercidas. Sin embargo, es necesario señalar los vicios de origen que dificultan el pleno ejercicio del mandato constitucional en materia limítrofe y que en última instancia determinan la posibilidad del Senado de la República, para preservar la paz, fortalecer las instituciones y la soberanía de las entidades federativas, otorgando a nuestro país la certeza y seguridad jurídica que se demanda sobre su territorio.

De entrada, se considera idónea la instancia del Senado por hacerse congruente con la preexistente facultad de admitir nuevos estados a la federación o resolver sobre la creación de entidades en el territorio mexicano; aunado ello a su responsabilidad como defensor del orden Federal y también por ser una medida que tiene toda la intención de fortalecer el Pacto Federal.

Ahora bien, al conferírsele una facultad que hasta el momento había sido limitada a la intervención en cuanto a los convenios amistosos y ampliarse su actuar no solo como mediador, sino también como órgano encargado de la resolución definitiva de estos conflictos; surge una necesidad, que es precisamente el establecimiento de un procedimiento claro y en atención a la justicia; que por la vía legislativa procure la prevalencia del Estado de Derecho en relación con la territorialidad de las Entidades que conforman esta Federación.

Los medios idóneos para la resolución de un conflicto limítrofe, no le fueron dotados al Senado, que adquirió una facultad materialmente jurisdiccional, aunque formalmente legislativa, lo cual, representó una situación atípica, pero constitucional.

Claramente, la división de poderes tiene hoy que incluir otros aspectos junto a las tradicionales funciones del Estado, en consecuencia, es necesaria la colaboración y el control recíproco entre el Ejecutivo, el Legislativo y el Judicial. Esto no significa que el mantenimiento y la funcionalidad jurídico-política de la división clásica de los tres poderes carezca (sic) de significación, sino que simplemente ha modificado su sentido.

Así pues, admitiendo como viables y necesarias estas atemperanzas - es decir el ejercicio material de una función distinta a la eminentemente originaria de un poder constituido, sin que por ello pierda su formalidad- es necesario también señalar que la facultad contenciosa otorgada al Senado de la República no fue acompañada de algunas de las atribuciones necesarias.

En particular, es de señalarse que no se contaba con los medios idóneos para:

${ }^{20}$ Op.Cit. 17..

CIENCIA JuRÍDICA. Departamento de Derecho. División de Derecho Política y Gobierno, Universidad de Guanajuato - Año 1, No. 2, 2012 
a) Someter a los estados al mandato del Senado de la República;

b) Determinar el estatus jurídico de las zonas limítrofes controvertidas;

c) Suspender los actos de cualquiera de las entidades sobre el área limítrofe;

d) Designar un responsable (V.Gr. la Federación) para la prestación de servicios básicos en el área limítrofe controvertida, y

e) Hacer ejecutar la resolución definitiva e inatacable del Senado, entre otras.

Las anteriores deficiencias, tienen su origen en el texto constitucional propuesto, es decir, aunque sean abordadas por una ley reglamentaria, el Senado no puede arrogarse, por ejemplo, de facultades de suspensión. ${ }^{21}$

Los anteriores argumentos, que en mucho son mas una justificación no solicitada acerca del porqué la reforma constitucional de 2005 no funcionó, vuelven a fijar en el debate el tema de si la facultad de dirimir los conflictos de límites entre las entidades federativas, constituye el dirimir un conflicto de índole político o jurídico.

\subsection{DICTAMEN DE LA CÁMARA DE DIPUTADOS}

La Comisión de Puntos Constitucionales de la Cámara de Diputados suscribió dictamen en sentido positivo, destacando que la principal novedad de la Minuta es regresar a la Suprema Corte de Justicia de la Nación, la facultad para resolver controversias en materia de conflictos sobre límites territoriales, argumento que se hiló con la reforma constitucional de 1994, por lo que hace al tema de la controversia constitucional, citando la parte conducente de la iniciativa del Presidente Ernesto Zedillo Ponce de León:

«La iniciativa plantea la reforma del artículo 105 constitucional a fin de ampliar las facultades de la Suprema Corte de Justicia de la Nación para conocer de las controversias que se susciten entre la federación, los estados y lo municipios; entre el Ejecutivo federal y el Congreso de la Unión; entre los Poderes de las entidades federativas, o entre los órganos de gobierno del Distrito Federal, al ampliarse la legitimación para promover las controversias constitucionales, se reconoce la complejidad que en nuestros días tiene la integración' de los distintos órganos federales, locales y municipales. $»^{22}$

Sosteniendo este argumento con el contenido de la tesis P./J. 97/2007, de la Novena Época, del Pleno de nuestro Máximo Tribunal, publicada en el Semanario Judicial de la Federación y su Gaceta, Tomo XXVI, de diciembre de 2007, página 1101, bajo el rubro y texto siguientes:

Controversia constitucional. Procede contra las resoluciones de las legislaturas locales que dirimen en definitiva conflictos de límites territoriales entre los municipios de un estado. Conforme a los artículos 46, 73, 76 y 105 de la Constitución Política de los Estados Unidos Mexicanos, la Cámara de Senadores del Congreso de la Unión está facultada para resolver de manera definitiva e inatacable los conflictos que por límites territoriales se susciten entre los Estados de la Federación, lo que se corrobora con el primer párrafo de la fracción I del indicado artículo 105, que prevé que los conflictos a que se refiere el artí-

\footnotetext{
${ }^{21}$ Op. Cit. 17 .

${ }^{22}$ Dictamen de la Comisión de Puntos Constitucionales, con proyecto de decreto que reforma los artículos 46, 76 y 105 de la Constitución Política de los Estados Unidos Mexicanos. Gaceta Parlamentaria de la Cámara de Diputados. Año XV, número 3497-II, del martes 24 de abril de 2012. Consultable en: http://gaceta.diputados. gob.mx/
} 
culo 46 del propio Ordenamiento Fundamental no pueden impugnarse en controversia constitucional; asimismo, el citado artículo 105 faculta a la Suprema Corte de Justicia de la Nación para conocer a través del mencionado medio de control constitucional, a instancia de parte interesada, de los conflictos derivados de la ejecución de los decretos que emita el Senado en materia de límites territoriales estatales. Ahora bien, tratándose de las resoluciones de las Legislaturas Locales en materia de delimitación territorial de los Municipios de un Estado, como la propia Constitución Federal no establece la improcedencia de la controversia constitucional respecto de estas resoluciones, no existe impedimento alguno para que este Alto Tribunal revise en esa vía las resoluciones dictadas en la indicada materia, pues de lo contrario se haría nugatorio el procedimiento que tiene como fin primordial garantizar la supremacía de la Ley Fundamental, ajustando el actuar de cualquier autoridad a los lineamientos que ésta prevé, máxime si dichas determinaciones pueden afectar de manera directa o indirecta las prerrogativas constitucionales otorgadas a algún Poder o nivel de gobierno.

Consignando el dictamen de la colegisladora que:

«En suma, esta colegisladora llega a la firme convicción de que el Senado de la República, invade materialmente las facultades del Poder Judicial establecidas en el artículo 105 constitucional, al convertirse en un tribunal especial, prohibido por el artículo 13 de la ley fundamental.

Esto es así, ya que la reforma constitucional de 2005, a los artículos 46, 76 y 105, que le dan competencia al Senado de la República para conocer de conflictos en materia de límites territoriales, facultad que tenía la Suprema Corte, actualmente vulneran la autonomía de este órgano jurisdiccional, al convertirlo en un órgano ejecutor del cumplimiento de las decisiones del Senado la República, por ello, es importante devolver a la Corte su facultad original como principio del respeto y autonomía de los Poderes de la Unión.» ${ }^{23}$

Se destaca que el Decreto aprobado por la Cámara de Diputados — la cual al haber fungido como cámara revisora turnó la Minuta Proyecto de Decreto a las legislaturas de los estados- aprobó en sus términos los artículos transitorios de la Minuta:

«Único. El presente decreto entrará en vigor el día siguiente al de su publicación en el Diario Oficial de la Federación, y quedarán derogadas todas las disposiciones normativas que contravengan a este Decreto.»

\section{CRÍTICA A LA REFORMA CONSTITUCIONAL DE 2005, A MANERA DE CONCLUSIÓN}

La norma jurídica no es un instrumento estático, sino por el contrario, debe permanecer en un proceso constante de cambio, de perfeccionamiento, para resolver, por una parte las probables deficiencias y lagunas que contenga y para que su contenido se mantenga acorde a la realidad que le corresponde regular. Esta dinámica de cambio normativo posibilita que la Norma Fundamental se encuentre cotidianamente sujeta a escrutinio.

Bajo este contexto, y acorde al análisis desarrollado, se considera que la reforma constitucional de publicada en el Diario Oficial de la Federación el 8 de noviembre de 2005, fue una reforma mal planeada y peor ejecutada, por las siguientes razones:

\footnotetext{
${ }^{23}$ Op. Cit. 21
} 
a) Un tema de carácter jurisdiccional, como es la resolución de límites territoriales entre las entidades federativas a cargo de la Suprema Corte de Justicia de la Nación, se trasladó a un tema político, como atribución del Senado de la República, desnaturalizando la función decisoria. Ilustra la falta de previsión de esta reforma, lo aducido hace más de ciento cincuenta años, cuando en los debates del constituyente de 1857 , al darse lectura al dictamen de la comisión de división territorial, en diciembre de 1856, consignó Isidro A. Montiel y Duarte, en su obra Derecho Público Mexicano:

«El Sr. Ramírez (D. Ignacio), califica de inútil el artículo, y ántes (sic) de entrar en la cuestión hace la más triste reseña de los trabajos de la gran comisión parlamentaria. La circunstancia de componerse de un diputado por cada Estado, impidió toda reforma radical é (sic) hizo que se adoptara el plan de conservar lo existente, proponiéndose conquistar cada cual para su Estado.» ${ }^{24}$

Aunado a la crítica anterior, se destaca que el Senado, desde sus inicios ha tenido como misión, ser representante de las entidades federativas, en su carácter autonómico ante cualquier conflicto, pero de índole político, sin embargo la paridad con que teóricamente debiera contar cada entidad federativa al tener por citar un ejemplo, Chihuahua y Tlaxcala -la entidad más grande y la más pequeña en territorio- o el Estado de México y Baja California Sur -la entidad más poblada y la menos poblada-, el mismo número de senadores, se ha roto con la incorporación del cuarto senador por entidad federativa, con la reforma constitucional de 1996.

b) Si bien el Senado integró la Comisión de Asuntos de Límites Territoriales, al encontrarse su labor sustantiva - sancionar los acuerdos amistosos de las entidades federativas, y proponer la resolución de límites territoriales - sujeta a que se cuente con una Ley Reglamentaria que prevea el procedimiento, y al no haberse emitido ésta por el propio Senado de la República, ha hecho nugatorio su trabajo.

Implícitamente así se reconoce en el Plan de Trabajo de la Comisión de Límites de las entidades Federativas:

«Como es evidente, el Senado de la República y particularmente la CLEF, tienen una oportunidad histórica, no sólo para esclarecer problemas ancestrales de nuestro país, sino para fortalecer el pacto federal, dotando de certeza a las entidades y la federación. Sin embargo, el ejercicio de tan trascendente facultad estará limitado y enmarcado por lo que establezca la Ley Reglamentaria en la materia, obligación constitucional del Congreso de la Unión, que aun no ha sido satisfecha.

Así las cosas, la prioridad y condición sine qua non para asumir este encargo, es la aprobación de la referida Ley, misma que contendrá las herramientas para iniciar la resolución de los asuntos limítrofes pendientes.» ${ }^{25}$

De modo que hasta en tanto no se contara con una Ley Reglamentaria, la labor de la Comisión de Límites Territoriales, carecía de «sustancia», por ende, la crítica es al total de los inte-

\footnotetext{
${ }^{24}$ Op. Cit. 4, p. 533..

${ }^{25}$ Consultable en: http://www.senado.gob.mx/libreria/web/comisiones/LEF/index.php?ver=1.1 
grantes del Senado de la República que incumplieron con el mandato constitucional de dotar de una Ley Reglamentaria a la Comisión de Asuntos de Límites Territoriales. ${ }^{26}$

Ello, configura lo que en opinión de algunos tratadistas de derecho procesal constitucional se ha dado en llamar en la doctrina, inconstitucionalidad por omisión legislativa, por tratarse la expedición de la Ley Reglamentaria en materia de Límites Territoriales, de una norma de eficacia diferida ${ }^{27}$ al necesitar ser actuada o concretada a través de una posterior actividad normativa.

c) Conforme al artículo segundo transitorio del decreto de reforma constitucional de 2005, la SCJN acató el mandato del Constituyente Permanente y turnó los expedientes de las controversias constitucionales que estaban en trámite antes de la promulgación de la citada reforma al Senado de la República:

- 09/97: Quintana Roo Vs. Yucatán y Campeche;

-13/97: Quintana Roo Vs. Yucatán y Campeche;

- 03/98: Jalisco Vs. Colima; y

- 51/o4: Municipios de Cihuatlán, Jalisco Vs. Manzanillo, Colima.

No obstante, dichas controversias quedaron insubsistentes ante la Corte, en virtud del auto de sobreseimiento que sobre cada una de ellas recayó atendiendo lo dispuesto por el artículo tercero transitorio de la reforma de 2005 , que a la letra señala:

"Artículo Tercero. Las controversias que a la entrada en vigor de este decreto se encuentren en trámite ante la Suprema Corte de Justicia de la Nación con motivo de conflictos limítrofes entre entidades federativas, serán remitidas de inmediato, con todos sus antecedentes, a la Cámara de Senadores, a fin de que ésta en términos de sus atribuciones constitucionales proceda a establecerlos de manera definitiva mediante decreto legislativo.»

Así pues, la Suprema Corte de Justicia de la Nación dejó de conocer las controversias previamente admitidas, quedando insubsistentes sus facultades en materia limítrofe, por lo que lo jurídicamente correcto era darle un final a ese proceso, hecho que se materializó en el año 2005, con los referidos autos de sobreseimiento.

Los asuntos fueron turnados al Senado de la República, que recibió los expedientes como antecedentes, para en un momento posterior proceder al estudio de cada uno de esos temas y determinar en definitiva los límites entre las entidades afectadas; y dado que para ejercer plenamente sus facultades limítrofes, las mismas debían ser reglamentadas mediante una ley constitucional, la aprobación de tal ley era indispensable para ejercer la facultad exclusiva consagrada en la fracción XI del artículo 76 constitucional (procedimiento contencioso), pues resultaba necesario establecer un procedimiento por ley que respetara las garantías esenciales del proceso, y salvaguardara el derecho de las entidades a ser oídas y vencidas ante la instancia facultada para resolver sus conflictos.

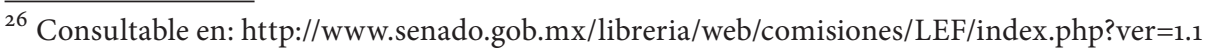

27 Son normas de organización de los llamados «poderes» estatales y de sus instancias de dirección. Ver Báez Silva, Carlos, La inconstitucionalidad por omisión legislativa en México, México, D.F., 20oo, ed. Porrúa, p. 14. 
En consecuencia, se perdieron más de seis años de inactividad en el Senado por la falta de acuerdos para sacar adelante la Ley Reglamentaria en materia de Límites Territoriales, generando con ello además un problema para la Suprema Corte de Justicia de la Nación que tendrá que reanudar y resolver los expedientes de conflictos de límites, sin actividad procesal en más de seis años.

7. BIBLIOGR AFÍA

BÁEZ SILVA, Carlos. La inconstitucionalidad por omisión legislativa en México, México, D.F., Porrúa e Instituto Mexicano de Derecho Procesal Constitucional, 2009, ed. Porrúa.

CRUZ BARNEY, Oscar. Comentario al artículo 47 en Constitución Política de los Estados Unidos Mexicanos, Comentada y concordada. México, D.F., Tomo II, Vigésima edición. Instituto de Investigaciones Jurídicas de la U.N.A.M., 2009, ed. Porrúa.

GALEANA, Patricia comp., México y sus Constituciones. México, D.F., 1999, ed. Archivo General de la Nación y Fondo de Cultura Económica.

MONTIEL y DUARTE, Isidro Antonio. Derecho Público Mexicano, Compilación. México, D.F., Tomos I, II, III y IV, 1871, ed. Imprenta del Gobierno en Palacio.

NORIEGA, Celicilia y Salmerón, Alicia, comps. México: un siglo de historia constitucional (1808-1917): estudios y perspectivas, México, D.F., 2009. Instituto de Investigaciones Dr. José María Luis Mora y Suprema Corte de Justicia de la Nación.

Secretaría General del Congreso del Estado y Dirección General de Apoyo Parlamentario. Constitución Política de los Estados Unidos Mexicanos, Historia Legislativa (19171999). Guanajuato, Gto., 200o. Comisión de Régimen Interno, Congreso del Estado de Guanajuato, LVII Legislatura.

TORIJA AGUILAR, Jaime et al. El senado mexicano. Por la razón de las leyes, 2010. México, D.F., Volumen uno. 1987. Senado de la República, LIII Legislatura.

Comisión de Límites de las Entidades Federativas del Senado de la República. Plan General de Trabajo, LXI Legislatura. Consultable en: http://www.senado.gob.mx/libreria/ web/comisiones/LEF/index.php?ver $=1.1$

Dictamen de la Comisión de Puntos Constitucionales, con Proyecto de Decreto que reforma el único párrafo y se adicionan un segundo y tercer párrafos al artículo 46; se deroga la fracción IV del artículo 73; se adicionan las fracciones X y XI, pasando la actual fracción X a ser fracción XII, del artículo 76; y se reforma la fracción I del artículo 105 de la Constitución Política de los Estados Unidos Mexicanos. Gaceta Parlamentaria de la Cámara de Diputados del H. Congreso de la Unión del 28 de abril de 2005. Consultable en: http:/gaceta.diputados.gob.mx/ 
Dictamen de las Comisiones Unidas de Puntos Constitucionales; y de Estudios Legislativos, Primera, el que contiene proyecto de decreto mediante el cual se reforma el único párrafo y se adicionan un segundo y tercer párrafos al artículo 46; se deroga la fracción IV del artículo 73; se adicionan las fracciones X y XI, pasando la actual fracción $\mathrm{X}$ a ser fracción XII del artículo 76; y se reforma la fracción I del artículo 105, todos de la Constitución Política de los Estados Unidos Mexicanos. Gaceta Parlamentaria del Senado de la República del 21 de junio de 2005. Primer Periodo Extraordinario, Número de Gaceta: 113. Consultable en: http://www.senado.gob.mx/index.php?ver= $\mathrm{sp} \& \mathrm{mn}=2 \& \mathrm{sm}=2 \& \mathrm{id}=6781 \& \lg =59$

Dictamen de la Comisión de Puntos Constitucionales, con proyecto de decreto que reforma los artículos 46, 76 y 105 de la Constitución Política de los Estados Unidos Mexicanos. Gaceta Parlamentaria de la Cámara de Diputados. Año XV, número 3497-II, del martes 24 de abril de 2012. Consultable en: http://gaceta.diputados.gob.mx/

Constitución Política de los Estados Unidos Mexicanos. 


\section{Anexo 1}

\begin{tabular}{|c|c|c|c|c|}
\hline Texto Vigente & $\begin{array}{l}\text { Iniciativa Senador } \\
\text { Ramiro Hernández }\end{array}$ & $\begin{array}{l}\text { Iniciativa Senador } \\
\text { Humberto Andrade }\end{array}$ & $\begin{array}{l}\text { Iniciativa Senadores } \\
\text { de la Junta de } \\
\text { Coordinación Política }\end{array}$ & $\begin{array}{l}\text { Iniciativa Senador } \\
\text { Héctor Pérez Plazola }\end{array}$ \\
\hline $\begin{array}{l}\text { Artículo 46. Las } \\
\text { entidades federativas } \\
\text { pueden arreglar entre } \\
\text { sí, por convenios } \\
\text { amistosos, sus respec- } \\
\text { tivos límites; pero no } \\
\text { se llevarán a efecto } \\
\text { esos arreglos sin la } \\
\text { aprobación de la Cá- } \\
\text { mara de Senadores. }\end{array}$ & Artículo 46. (...) & $\begin{array}{l}\text { Artículo } 46 . \text { Las } \\
\text { entidades federativas } \\
\text { pueden arreglar entre } \\
\text { sí, por convenios } \\
\text { amistosos, sus respec- } \mathrm{r} \\
\text { tivos límites, de los } \\
\text { cuales se dará parte a } \\
\text { la Cámara de Senado- } \\
\text { res y al Titular del Po-1 } \\
\text { der Ejecutivo, a fin de } \\
\text { que sean publicados } \\
\text { en el Diario Oficial dec } \\
\text { la Federación. }\end{array}$ & $\begin{array}{l}\text { Artículo 46. La } \\
\text { Suprema Corte de } \\
\text { Justicia de la Nación, } \\
\text { conocerá, sustancia- } \\
\text { rá y resolverá con } \\
\text { carácter inatacable, } \\
\text { los conflictos sobre } \\
\text {-límites territoria- } \\
\text {-les que se susciten } \\
\text { entre las entidades } \\
\text { federativas, a petición } \\
\text { de parte, y por la vía } \\
\text { de la controversia } \\
\text { constitucional en los } \\
\text { términos del artículo } \\
105 \text { fracción I de esta } \\
\text { Constitución }\end{array}$ & $\begin{array}{l}\text { Artículo 46.- Los con- } \\
\text { flictos que se susciten } \\
\text { entre las entidades } \\
\text { federativas sobre } \\
\text { límites territoriales, } \\
\text { serán resueltos por } \\
\text { la Suprema Corte de } \\
\text { Justicia de la Nación a } \\
\text { través de la contro- } \\
\text { versia constitucional, } \\
\text { en los términos de la } \\
\text { fracción I del artículo } \\
105 \text { de esta Consti- } \\
\text { tución. }\end{array}$ \\
\hline $\begin{array}{l}\text { A falta de acuerdo, } \\
\text { cualquiera de las par- } \\
\text { tes podrá acudir ante } \\
\text { la Cámara de Senado- } \\
\text { res, quien actuará en } \\
\text { términos del artículo } \\
76 \text {, fracción XI, de } \\
\text { esta Constitución. }\end{array}$ & $\begin{array}{l}\text { A falta de acuerdo, o } \\
\text { cuando dicho acuer- } \\
\text { do no se apruebe } \\
\text { - por la Cámara de } \\
\text { Senadores, cual- } \\
\text { quiera de las partes } \\
\text { podrá acudir ante la } \\
\text { Suprema Corte de } \\
\text { Justicia de Nación, en }\end{array}$ & $\begin{array}{l}\text { A falta de acuerdo, } \\
\text { cualquiera de las } \\
\text { partes podrá acudir } \\
\text { ante la Suprema Corte } \\
\text { de Justicia de Nación, } \\
\text { en la vía de contro- } \\
\text { versia constitucional, } \\
\text { quien actuará en } \\
\text { términos del artículo }\end{array}$ & & \\
\hline $\begin{array}{l}\text { Las resoluciones del } \\
\text { Senado en la materia } \\
\text { serán definitivas e } \\
\text { inatacables. La Supre- } \\
\text { ma Corte de Justicia } \\
\text { de la Nación podrá } \\
\text { conocer a través de } \\
\text { controversia consti- } \\
\text { tucional, a instancia } \\
\text { de parte interesada, } \\
\text { de los conflictos deri- } \\
\text { vados de la ejecución } \\
\text { del correspondiente } \\
\text { decreto de la Cámara } \\
\text { de Senadores. }\end{array}$ & $\begin{array}{l}\text { la vía de controversia } \\
\text { constitucional. }\end{array}$ & $\begin{array}{l}\text { 105, fracción I, de } \\
\text { esta Constitución. }\end{array}$ & & \\
\hline
\end{tabular}




$\begin{array}{lllll}\begin{array}{l}\text { Artículo 76. Son } \\ \text { facultades exclusivas } \\ \text { del Senado: }\end{array} & \begin{array}{l}\text { Artículo 76. Son } \\ \text { facultades exclusivas } \\ \text { del Senado: }\end{array} & \begin{array}{l}\text { Artículo 76. Son } \\ \text { facultades exclusivas } \\ \text { del Senado: }\end{array} & \begin{array}{l}\text { Artículo 76. Son } \\ \text { facultades exclusivas } \\ \text { del Senado: }\end{array} & \begin{array}{l}\text { Artículo 76.- Son } \\ \text { facultades exclusivas } \\ \text { del Senado: }\end{array} \\ \begin{array}{ll}\text { I a IX. (...) } & \text { I a IX. (...) }\end{array} & \text { I a IX. (...) } & \text { I a IX. (...) } & \text { I a IX. (...) }\end{array}$

X. Autorizar median- X. Autorizar median- X. Autorizar median- X. Autorizar median- X. Se deroga te decreto aprobado te decreto aprobado te decreto aprobado te decreto aprobado por el voto de las dos por el voto de las dos por el voto de las dos por el voto de las dos terceras partes de los terceras partes de los terceras partes de los terceras partes de los individuos presen- individuos presen- individuos presen- individuos presentes, los convenios tes y escuchando la tes, los convenios tes, los convenios amistosos que sobre opinión técnica de amistosos que sobre amistosos que sobre sus respectivos límiteslos Comités Técnicos sus respectivos límitessus respectivos límites celebren las entidades Especiales de Esta- celebren las entidades celebren las entidades federativas; dística y de Informa- federativas; federativas; ción Geográfica, los convenios amistosos que sobre sus respectivos límites celebren las entidades federativas, dentro de los ciento veinte días naturales siguientes a la presentación de dicho convenio; $y$

XI. Resolver de manera definitiva los conflictos sobre

XI. Resolver de manera definitiva los conflictos sobre límites territoriales de las entidades federativas que así lo soliciten, mediante decreto aprobado por el voto de las dos terceras partes de los individuos presentes;

XII. Las demás que la misma Constitución le atribuya.

\section{límites territoriales} de las entidades federativas que así lo soliciten, mediante decreto aprobado por el voto de las dos terceras partes de los individuos presentes;

XII. Las demás que la misma Constitución le atribuya.
XI. Resolver de manera definitiva los conflictos sobre límites territoriales de las entidades federativas que así lo federativas que así lo soliciten, mediante soliciten, mediante decreto aprobado decreto aprobado por el voto de las dos por el voto de las dos terceras partes de los terceras partes de los individuos presentes; individuos presentes; XII. (...)

\section{Se deroga} manera definitiva los conflictos sobre límites territoriales de las entidades XII. (...) XII. (..) 
Artículo 105. LaArtículo 105.(..) Artículo 105. (..) Artículo 105. (..) Artículo 105. (...) Suprema Corte de Justicia de la NaciónI. De las controversiasI. De las controversiasI. De las controversiasI. De las controverconocerá, en los tér-constitucionales que,constitucionales que,constitucionales que,sias constitucionales minos que señale lacon excepción de lascon excepción de lascon excepción de lasque, con excepción ley reglamentaria, deque se refieran a laque se refieran a laque se refieran a lade las que se refieran los asuntos siguientes:materia electoral $\mathbf{y}$ amateria electoral $\mathbf{y}$ amateria electoral $\mathbf{y}$ a a la materia electoral

lo establecido en ello establecido en ello establecido en ely a lo establecido en I. De las controver-artículo 46 de estaartículo 46 de estaartículo 46 de estael artículo 46 de esta sias constitucionalesConstitución, se sus-Constitución, se sus-Constitución, se sus-Constitución, se susque, con excepciónciten entre: citen entre: citen entre: citen entre: de las que se refieran
a la materia electorala) a k)
a) a k)
a) a k)
a) a k)
y a lo establecido en el artículo 46 de esta Constitución, se sus-( citen entre: II y III. (...)
)(

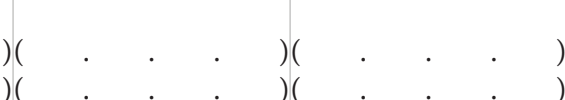
a) a k)
$(\cdot+\cdot)$

II y III. (...) 